\title{
Detection of Enrofloxacin Residue in Livers of Livestock Animals Obtained from a Slaughterhouse in Mosul City
}

\section{Iqbal A. Sultan*}

Department of Veterinary Public Health, College of Veterinary Medicine, University of Mosul, Iraq

\begin{abstract}
Ninety liver samples of poultry, sheep and cattle, 30 each, were obtained from meat retail markets at Mosul city in Iraq, and were analyzed for enrofloxacin residue by using Enzyme Linked Immunosorbent Assay, ELISA [ Schen Zhen Lvshiynan Biotechnology Co., LTD. (china)].

The study revealed that the range and mean of residual enrofloxacin drug concentration in the examined liver samples of poultry, cattle and sheep were (0.01-10.69) (4.290); (0.03-3.61) (1.750); (0.02-1.32) (1.687) mg/ $\mathrm{kg}$ respectively. Also the study revealed that $30(33.31 \%)$ of poultry liver samples tested positive, $8(8.88 \%)$ of cattle samples were positive, and $5(5.55 \%)$ of sheep samples were positive for enrofloxacin. $17(56.66 \%)$ of the poultry samples exceeded the maximum residues limits (MRL), as did $8(26.61 \%)$ of cattle samples, and $5(16.6 \%)$ of sheep samples. Our results have shown that the maximum mean enrofloxacin concentration was found in poultry livers (4.290) and the minimum mean was in the ovine liver samples (1.687) while bovine livers were (1.750). The difference between the residue of enrofloxacin of poultry liver samples and that of bovine and ovine liver samples was significant at $(P<0.05)$.
\end{abstract}

Keywords: Enrofloxacin; Residue; Farm animals; ELISA; Liver

\section{Introduction}

Enrofloxacin is one of the third generation members of the fluoroquinolone antibacterial agents. Fluoroquinolones (FQs) are highly effective synthetic antibiotics. Their therapeutic mechanism of actions are based on the inhibition of DNA gyrase in gram-negative species and topoisomerase IV in gram-positive species [1,2]. They have been recommended for the treatment of urinary tract and enteric infections in humans. These drugs are normally prescribed for the treatment and prevention of infectious diseases in farm animals. In addition, it is routinely considered as a protective measure when raising animals under intensive husbandry production methods [3]. Moreover, they have also been used in sub-therapeutic levels as feed additives for promoting and protecting normal growth of meat production livestock [4].

Enrofloxacin is an antibiotic that is very useful against a wide variety of infections in animals and used as a prophylaxis or treatment of infectious diseases. Also, the high level usage of this drug in animals and humans, or the use of less potent quinolones, particularly in developing countries, has been attributed to the rapid development of bacterial resistance to these agents combined with less withdrawal time of antibiotics in meat producing industry. Existence of antibiotic residues in food stuff can pose hazards to human health, including sensitivity to antibiotics, allergic reactions and imbalance of intestinal micro flora, bacterial resistance to antibiotics in microorganisms, as well as in the food industry [5]. Hence, routine quality assurance of food stuff regarding antibiotic residues is warranted [1]. European Union (EU) countries establishes a maximum residue level (MRL) of $30 \mathrm{ng} / \mathrm{g}$ of muscle, liver and kidney tissue for the sum of enrofloxacin and its metabolite ciprofloxacin [6].

Screening methods for FQs in foods of animal origin include microbial growth inhibition [7], microbial receptor assay, enzyme linked immunosorbent assay (ELISA) [8], thin layer chromatography (TLC) [9] and others $[10,11]$. It is extremely important to protect treated food destined for human consumption. The purpose of this study was to analyse a large number of samples without purification procedures that are required by application of ELISA technique for detection of residual enrofloxacin.

\section{Materials and Methods}

\section{Collection of samples}

Ninety liver samples of sheep, cow and poultry (30 from each species) were purchased from meat retail markets at Mosul city in Iraq. Liver samples were wrapped in polyethylene bags packed in a cool box with a dry ice and transported immediately (within 1 hour maximum) to the laboratory at the Veterinary Public Health Department of the College of Veterinary Medicine in Mosul.

\section{Preparation of samples}

Two grams of homogenized liver were poured into a $50 \mathrm{ml}$ tube. The contents of the tube were mixed with $8 \mathrm{ml}$ dissolving solution (Shenzhen Lvshiynan Biotechnology Co., LTD). This solution was prepared by diluting $2 \mathrm{x}$ concentrated redissolving solution with deionised water at a 1:1 ratio and mixing with Acetonitrite $(\mathrm{CH} 3 \mathrm{CN})$ - Methylene Chloride of 1:3 (V. acetonitrite- V. methylene chloride $=1: 3$ ). This mixture was shaken for 5 minutes and the tubes were then centrifuged at $4000 \mathrm{rpm}$ for 10 minutes at $15^{\circ} \mathrm{C}$.

Two millilitres $(\mathrm{ml})$ of clear supernatant (upper layer) were transferred into a dry container and left to dry under nitrogen or air using rotatory evaporation at $50^{\circ} \mathrm{C}$. The dry residue was then dissolved

${ }^{*}$ Corresponding author: Iqbal A. Sultan, Department of Veterinary Public Health, College of Veterinary Medicine, University of Mosul, Iraq, Tel: 964-770-160-5334; Email:dr_iasmosul@yahoo.com

Received February 23, 2014; Accepted April 11, 2014; Published April 14, 2014

Citation: Sultan IA (2014) Detection of Enrofloxacin Residue in Livers of Livestock Animals Obtained from a Slaughterhouse in Mosul City. J Veterinar Sci Technol 5: 168. doi:10.4172/2157-7579.1000168

Copyright: (c) 2014 Sultan IA. This is an open-access article distributed under the terms of the Creative Commons Attribution License, which permits unrestricted use, distribution, and reproduction in any medium, provided the original author and source are credited. 
in $1 \mathrm{ml}$ of the diluted redissolving solution. $1 \mathrm{ml}$ of $\mathrm{N}$ - hexane was then added mixed for 30 seconds and centrifuged at $4000 \mathrm{rpm}$, at $15^{\circ} \mathrm{C}$, for over 5 minutes. The upper layer was then removed and $50 \mathrm{ml}$ of the lower layer were aliquot and stored at $-18^{\circ} \mathrm{C}$ for further analysis to detect enrofloxacin residues.

\section{Technique}

All the necessary reagents were brought to normal room temperature $\left(20-25^{\circ} \mathrm{C}\right)$ by lifting them for about 30 minutes. Concentrated washing buffer $(40 \mathrm{ml})$ was diluted with distilled or deionized water to $800 \mathrm{ml}$. $50 \mu \mathrm{l}$ aliquots of the samples or standard solution were placed in a separate duplicate wells to which another $50 \mu$ of the enzyme conjugate and antibody working solution $(50 \mu \mathrm{l})$ was added to the wells.

All the additives were mixed in the wells by gently shaking. The microplates were then sealed with cover membranes and incubated at $25^{\circ} \mathrm{C}$ for $1 \mathrm{hrs}$. After incubation the microplates were washed with washing buffer $250 \mu \mathrm{l} /$ well, 4-5 times. Subsequently, the substrate A solution $(50 \mu \mathrm{l})$ and solution $\mathrm{B}(50 \mu \mathrm{l})$ were added to each well. These solutions were mixed by gently shaking and then incubated at $25^{\circ} \mathrm{C}$ for 15 minutes in the dark. The reactions were finished by the addition of $50 \mu \mathrm{l}$ of stop solution (Schen Zhen Lvshiynan Biotechnology Co., LTD. (china) into each well, followed by shaking. The results were read at $450-630 \mathrm{~nm}$ at 5 minutes for OD values determination.

\section{Statistical analysis}

The data was analysed using a sigma state software (windows version $3.10 ; 2004$ ) the differences in means and percentages of samples exceeding the MRL limits were compared using one-way analysis of variance and Duncan's multiple range test. Differences of $<0.05$ were considered significant.

\section{Results}

The results of our study revealed that the ranges and means of residual enrofloxacin concentrations in the examined liver samples of poultry, cattle and sheep were $(0.01-10.69 ; 4.290),(0.03-3.61 ; 1.750)$, (0.02-1.32; 1.687) $\mathrm{mg} / \mathrm{kg}$ respectively (Table 1 ).

Out of the 90 total liver samples, 30 (33.31\%) of the samples were

\begin{tabular}{|c|c|c|c|}
\hline $\begin{array}{c}\text { Type of examined } \\
\text { samples }\end{array}$ & $\begin{array}{c}\text { Number of } \\
\text { examined samples }\end{array}$ & Range & Mean \pm SEM \\
\hline Poultry liver & 30 & $0.01-10.69$ & $4.290^{\star} \mathrm{a} \pm 0.954$ \\
\hline Cattle liver & 30 & $0.03-3.61$ & $1.750^{*} \mathrm{~b} \pm 0.392$ \\
\hline Sheep liver & 30 & $0.02-1.32$ & $1.687^{*} \mathrm{~b} \pm 0.519$ \\
\hline
\end{tabular}

${ }^{*} \mathrm{a}$ and ${ }^{*} \mathrm{~b}$ : the difference between the means that have common are significant $(p<0.05)$

Table 1: Comparison of range and mean concentrations of enrofloxacin in poultry, cattle, and sheep liver samples.

\begin{tabular}{|c|c|c|c|c|}
\hline $\begin{array}{c}\text { Type of examined } \\
\text { samples }\end{array}$ & $\begin{array}{c}\text { Number of } \\
\text { examined } \\
\text { samples }\end{array}$ & $\begin{array}{c}\text { Number of samples } \\
\text { exceeding the MRL } \\
\text { limits }\end{array}$ & $\begin{array}{c}\% \text { of samples } \\
\text { exceeding the } \\
\text { MRL Limits }\end{array}$ & $\%$ Total \\
\hline Poultry liver & 30 & 17 & 56.66 *a & 18.88 \\
\hline Cattle liver & 30 & 8 & 26.6 *b & 8.88 \\
\hline Sheep liver & 30 & 5 & 16.6 *b & 5.55 \\
\hline Total & 90 & 30 & 0.33 & 33.31 \\
\hline
\end{tabular}

*a and *b:the difference between the percentages of samples exceeding the MRL limits are significant $(p<0.05)$

Table 2: Number and percentages of poultry, cattle, and sheep liver samples exceeding the maximum residues limits MRL for enrofloxacin as proposed by European Commission (EC). positive for residual enrofloxacin reaction. 17 (18.88\%) were positive in poultry samples, $8(8.88 \%)$ in cattle samples, and the lowest was 5 (5.55\%) for sheep samples (Table 2).

The number and percentage of samples exceeded the maximum acceptable limits of residual enrofloxacin in liver ordained by EC, 2002 are illustrated in (Table 2).

It is clear from the data that 17 (56.66\%) of the poultry samples exceeded the EC limit of $(0-2 \mu \mathrm{g} / \mathrm{Kg})$; while eight of the cattle samples (26.61\%) were over labelled the limits, and only 5 samples $(16.6 \%)$ of sheep samples exceeded the limit.

\section{Discussion}

Our results have shown that the maximum mean of enrofloxacin concentration was found in the poultry liver (4.290), the minimum mean was in the sheep liver samples (1.687), while cattle was (1.750). The difference between the residue of enrofloxacin of poultry liver samples and that of cattle and sheep liver samples was significant at $(\mathrm{P}<0.05)$.

Our result were consistent with other studies $[1,12]$ regarding the highest mean of enrofloxacin residues in poultry liver samples. Thus, monitoring the residues of enrofloxacin in chickens is of great interest in the food safety of chickens orally treated with enrofloxacin.

In addition, we have shown that the number and percentage of poultry, cattle, and sheep liver samples exceeded the maximum acceptable limits of residual enrofloxacin in liver, ordained by EC, 2002.

The MRLs permitted by the European agency for the evaluation of medicinal products for enrofloxacin and its metabolite ciprofloxacin are $100-300 \mu \mathrm{g} / \mathrm{kg}$ in muscle, liver and kidney in bovine, porcine, rabbit, ovine and poultry species $[13,14]$.

Our results show that $56.66 \%$ of poultry liver samples were positive to enrofloxacin. This conclusion from this result a that enrofloxacin was heavily used in investigated poultry. They also suggest that the withdrawal time may be insufficient for this drug. Moreover, it was reported that mycotoxin contamination of broiler feed may increase the residual values of enrofloxacin in poultry carcasses [15]. The application of strict measures for maintaining the flocks in the farm until the elapsing of the withdrawal period will play a key factor in resolving the exposure of human being to antibiotic residues $[16,17]$.

The highest percentage of the MRL which exceed the limits in chicken liver samples was in agreement with Gad [18]. This may be because enrofloxacin is easily distributed from plasma into tissues [19] and the concentration is higher in liver than in breast muscles.

Petrovi [20] found our results were in line with enrofloxacin concentrations being 3.78 times higher in liver than in muscle $24 \mathrm{~h}$ after the beginning of treatment, and because enrofloxacin is the drug of choice for the treatment of avian mycoplasma CRD-AIR Saculitis [21]. It is not surprising that high enrofloxacin residues may found in poultry, with similar results on the distribution of enrofloxacin in the liver and muscle reported by others $[1,22]$. The present study found that the lower percentage exceeding the MRL limits was observed in cattle 8.88 , and the lowest was in ovine 5.55 , with no significant between them $\mathrm{p}<0.05$. The lower percentages in bovine and ovine may be due to the dilution factor of mycotoxin during grazing and a good withdrawal period of drug in these species. Our results coincide with Gab TMM [18] through his study on antibiotic residues in tissue of slaughtered animals. 
Citation: Sultan IA (2014) Detection of Enrofloxacin Residue in Livers of Livestock Animals Obtained from a Slaughterhouse in Mosul City. J Veterinar Sci Technol 5: 168. doi:10.4172/2157-7579.1000168

Page 3 of 3

\section{References}

1. Farahmand S,Aref S, Nordehr R, Rahim M, Fariba G (2007) Enrofloxacin Residue in Chicken Tissues from Tehran Slaughterhouses in Iran. Pakistan Journal of Nutrition 6: 409-413.

2. WeihaiXu, Xiaobin Zhu, Xinting Wang, Liping Deng, Gan Zhang (2006) Residues of enrofloxacin, furazolidone and their metabolites in Nile tilapia (Oreochromisniloticus). Aquaculture 254: 1-8.

3. Dipeolu MA, Alonge DO (2002) Residues of streptomycin sntibiotic in meat sold for human Consumption in some states of SW Nigeria. Arch. Zootec 51: 477480 .

4. Okerman L, van Hoof J, Debeuckelaere W (1998) Evaluation of the European four-plate test as a tool for screening antibiotic residues in meat samples from retail outlets. J AOAC Int 81: 51-56.

5. Lolo M, Pedreira S, Miranda JM, Vázquez BI, Franco CM, et al. (2006) Effect of cooking on enrofloxacin residues in chicken tissue. Food AdditContam 23: 988-993.

6. Posyniak A, Zmudzki J, Semeniuk S (2001) Effects of the matrix and sample preparation on the determination of fluoroquinolone residues in animal tissues. J Chromatogr A 914: 89-94

7. Ashwin H, Stead S, Caldow M, Sharman M, Stark J, et al. (2009) A rapid microbial inhibition-based screening strategy for fluoroquinolone and quinolone residues in foods of animal origin. Anal ChimActa 637: 241-246.

8. Huet AC, Charlier C, Tittlemier SA, Singh G, Benrejeb S, et al. (2006) Simultaneous determination of (fluoro)quinolone antibiotics in kidney, marine products, eggs, and muscle by enzyme-linked immunosorbent assay (ELISA). J Agric Food Chem 54: 2822-2827.

9. Juhel-Gaugain M, Abjean JP (1998) Screening of quinolone residues in pig muscle by planar chromatography. Chromatographia 47: 101-104.

10. Chen G (2012) Screening of fluoroquinolone residues in caprine milk using a 5-kg luminescence photometer. Journal of Food Analytical Methods 5: 11141120

11. Chen G, Du Y (2011) Screening of danofloxacin residue in bovine tissue by terbium-sensitized luminescence on c18 sorbent strips. J Agric Food Chem 59 1058-1062.
12. Shareef AM, James ZT, Yonis KM (2009) Detection of antibiotic residues in stored poultry products. Iraqi Journal of Veterinary Sciences 23: 45-48.

13. EMEA/MRL/388/98-Final (1998) Enrofloxacine (modificatio for bovine, porcine and poultry), summary report 2

14. Martinez M, McDermott P, Walker R (2006) Pharmacology of the fluoroquinolones: a perspective for the use in domestic animals. Vet $\mathrm{J} 172$ : 10-28.

15. Okerman L, Van Hende J, De Zutter L (2007) Stability of frozen stock solutions of beta-lactam antibiotics, cephalosporins, tetracyclines and quinolones used in antibiotic residue screening and antibiotic susceptibility testing. Anal ChimActa 586: 284-288.

16. Reyes-Herrera I, Schneider MJ, Cole K, Farnell MB, Blore PJ, et al. (2005) Concentrations of antibiotic residues vary between different edible muscle tissues in poultry. J Food Prot 68: 2217-2219.

17. McReynolds JL, Caldwell DY, McElroy AP, Hargis BM, Caldwell DJ (2000) Antimicrobial residue detection in chicken yolk samples following administration to egg-producing chickens and effects of residue detection on competitive exclusion culture (PREEMPT) establishment. J Agric Food Chem 48: 64356438.

18. Gad TMM (2012) Effect of age and sex ofanimal on the antibiotic residues in tissue of some slaughtered animals. Ph. D. Thesis, Faculty of Veterinary Medicine, Zagazig University.

19. Rodríguez-Díaz RC, Fernandez-Romero JM, Aguilar-Caballos MP, GómezHens A (2006) Determination of fluoroquinolones in milk samples by postcolumnderivatization liquid chromatography with luminescence detection. J Agric Food Chem 54: 9670-9676.

20. PetroviJelena BM, Upi V, Stefanovi S, Stojanovi D (2006) Residues of rnrofloxacin and its main metabolite ciprofloxacin in brolier chickens. ActaVeterinaria, 56: 497-506.

21. Elkholy HM, Elkomy AA, AwidatSK, Elmajdoud AA (2009) Tissue and Egg Residues and Adverse Effect of Two Oral Enrofloxacin Preparations; Baytril $\circledast$ and Enrotryl@. Global Veterinaria 3: 363-368.

22. Mohamed AH, SamahK (2013) Screening of Some Antibiotics and Anabolic Steroids Residues in Broiler Fillet Marketed in El-Sharkia Governorate, Vol: 10 